482

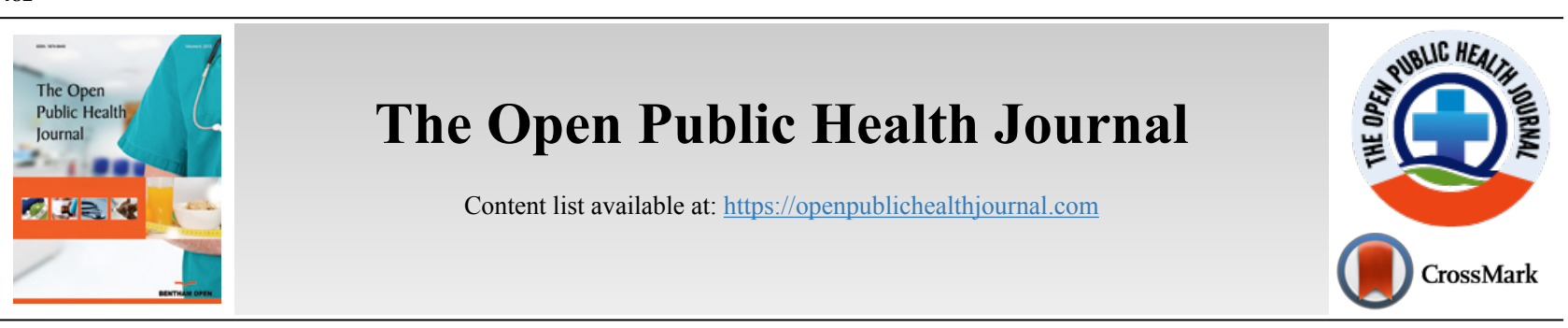

RESEARCH ARTICLE

\title{
Factors Affecting the Family Physicians' Intention to Leave the Job: A Case of Iran
}

\author{
Rita Rezaee ${ }^{1}$, Pegah Shoaahaghighi ${ }^{2}$, Najmeh Bordbar $^{3}$, Karam Tavani $^{4}$ and Ramin Ravangard ${ }^{5, *}$ \\ ${ }^{I}$ Department of Clinical Education Research Center, Health Human Resources Research Center, Shiraz University of Medical Sciences, Shiraz, Iran \\ ${ }^{2}$ Department of Health Education, Student Research Committee, Shiraz University of Medical Sciences, Shiraz, Iran \\ ${ }^{3}$ Department of Health Services Management, Student Research Committee, School of Management and Medical Information Sciences, Shiraz \\ University of Medical Sciences, Shiraz, Iran \\ ${ }^{4}$ Shiraz University of Medical Sciences, Shiraz, Iran \\ ${ }^{5}$ Department of Health Services Management, Health Human Resources Research Center, School of Management and Medical Information Sciences, \\ Shiraz University of Medical Sciences, Shiraz, Iran
}

\begin{abstract}
:
Background:

Family physician program is a complete health-care system, and its human resources are the most important resources like any other healthcare program. Organizational Commitment (OC) and Quality of Work-Life (QWL) are important factors in attracting and retaining employees.

Objective:

To investigate the association of OC and QWL with the intention to leave the job by family physicians in Shiraz, Iran in 2017.

Methods:

This was a descriptive analytical study conducted on a sample of 268 family physicians in 2017. For data collection, Porter's organizational commitment, Walton's Quality of Work Life, and Cammann's intention to leave the job questionnaires were used. The collected data were analyzed using SPSS 23.0.

Results:

The results showed that the levels of OC, QWL, and the intention to leave the job were moderate among the studied family physicians. In addition, the results showed that QWL and OC had negative and significant associations with the intention to leave the job ( $p$-value $<0.001)$, and the QWL had a greater association (Beta=-0.348).

Conclusion:

It is suggested that more attention should be paid to the family physicians at the Ministry of Health and the provincial level to improve the QWL and $\mathrm{OC}$ of the family physicians, and thereby preventing the physicians from leaving their job from the family physician program.
\end{abstract}

Keywords: Organizational commitment, Work-life, Job, Physicians, Family physician Program, Health service delivery.

Article History

Received: July 01, 2019

Revised: September 22, 2019

Accepted: October 29, 2019

\section{INTRODUCTION}

In recent years, one of the approaches taken to improve the health service delivery in Iran has been the family physician program. This program started in rural areas in 2005, and in

* Address correspondence to this author at Department of Health Services Management, Health Human Resources Research Center, School of Management and Medical Information Sciences, Shiraz University of Medical Sciences, Shiraz, Iran; Tel: 00987132340774; E-mail: ra_ravangard@yahoo.com
2011, it was implemented as a pilot program in Fars and Mazandaran provinces [1]. According to this program, family physicians, at the first level of providing health services and with the help of other health team members, are responsible for providing and managing the defined health service package for all individuals and families covered, usually up to 2500 people depending on the needs and circumstances of the region and regardless of the individuals' age, sex, socioeconomic charac- 
teristics, etc., and are mainly paid based on the capitation method. Policy makers believe that a well-functioning and comprehensive family physician program can play an important role in promoting public health, developing social justice, and establishing a comprehensive health care system [2]. Family physicians are responsible for providing health services to individuals and their families and work on finding and treating patients and preventing disabilities. Despite the importance of the healthcare team of the family physician program, the main burden of providing services is on the physicians [3]. In other words, according to the World Health Organization (WHO), family physicians are at the center of the global efforts to improve the quality of healthcare and make it cost-effective by bringing equity to healthcare systems [4].

On the other hand, an organization cannot reach a high level of performance, unless all employees are committed to its goals. Hence the concept of Organizational Commitment (OC) and its implications are important [5]. Meyer and Allen provided the most comprehensive concept of OC in the form of a three-dimensional model, including affective commitment (the emotional attachment to an organization), normative commitment (sense of obligation to remain in an organization), and continuous commitment (great desire to continue activities and membership in an organization) [5]. Organizational commitment studies revealed that employees with a higher organizational commitment increase the organization's ability to achieve its goals. Also, employees with higher commitment are more involved in their job activities, the probability of leaving their job is less likely, and have higher job motivation and satisfaction [6 - 9].

Moreover, the Quality of Work-Life (QWL) is a mental phenomenon influenced by personal perceptions and emotions. The QWL is a comprehensive plan to improve employees' satisfaction and to set real working conditions in an organization, such as fair and adequate salary, safe and hygienic work environment, providing opportunities for growth and sustained security, lawfulness in the organization, total space of life, unity and social cohesion, and development of human capabilities [10]. The results of various studies on the employees' QWL have shown that in organizations, the quality of QWL is essential for recruiting and retaining employees, which can enhance learning at work, better coping with changes in the environment, improve job performance and outcomes as well as job satisfaction. Organizations that provide better QWL are likely to be more successful in hiring and retaining employees [11 - 14]. Besides, high QWL creates an environment of mutual trust and respect, in which the employees can develop them psychologically, and the organization can reduce its rigid control mechanisms. On the contrary, poor QWL results in dissatisfaction and inappropriate behavior in employees [15].

On the other hand, the intention to leave the job is the employees' perception and desire to leave their occupations. Several factors affect the intention to leave the job [10]. Factors related to intention to leave the job by physicians are demographic characteristics, family and personal conflicts, work time and psycho-social conditions, social welfare, and job-related aspects. More specifically, factors such as having children, ethnicity, medical expertise, sex, age, work and family conflicts, on-call duties, hours of work, occupational stress, job satisfaction, job burnout, salary, quality of life, and in particular QWL [10 - 16].

As it was mentioned, human resources, as the most important component of health policies, have a great impact on the healthcare system, and the family physician program is no exception. Hence, retaining family physicians is a major challenge for healthcare planners and policymakers. If the family physician program fails to keep its physicians, most of the expected benefits, namely improving public health, developing social justice, and improving quality of life, cannot be achieved [17]. The results of some studies on the family physician program conducted in Iran have shown that the lack of motivational and economic factors, such as low and inadequate salaries and irregular payments, as well as environmental and working factors such as inappropriate and long working hours, high workload, job insecurity, high job responsibilities, lack of opportunities for continuing education, etc. are some of the main problems of family physicians [1719], so that in one study, the results showed that more than a quarter of studied family physicians had left out the program in the past and more than two-thirds of family physicians were willing to leave their job in the near future [17].

Since the researchers did not find a comprehensive study on the associations of OC and QWL with the intention to leave the job by family physicians, the present study aimed to investigate their associations with the Shiraz family physicians' intention to leave their job in 2017.

\section{METHODS}

This was a cross-sectional and descriptive-analytic study conducted in 2017 in order to investigate the association of OC and QWL to leave the job by family physicians in Shiraz, Iran, in 2017. The study population consisted of 671 family physicians in Shiraz, Iran. According to the results of the pilot study and using the following sample size formula, assuming $\alpha=0.05, \mathrm{~S}=0.4$, and $\mathrm{d}=0.05$, the sample size was determined at 245 . For the purpose of increasing the accuracy and taking into account, the $10 \%$ dropouts, the sample size was considered at 268 family physicians. The samples were selected randomly from the list of available family physician profiles using a random number table.

$$
\mathrm{n}=\frac{\mathrm{Z}_{1-\frac{\alpha}{2}}^{2} \mathrm{~S}^{2}}{\mathrm{~d}^{2}}
$$

Where $\mathrm{Z}=$ the critical value and the statistic corresponding to the level of confidence, $S^{2}=$ the variance of the intention to leave the job in the pilot study sample, and $d=$ the degree of precision.

In order to collect the required data, three different questionnaires were used: The Porter's Organizational Commitment Questionnaire, which included 15 questions in three dimensions of continuous commitment, affective commitment, and normative commitment, to measure the organizational commitment [20], in which the mean score of 
less than 35 was considered low, between 35 and 55 as moderate and higher than 55 as high; the Walton's Quality of Work Life Questionnaire which included 26 items covering eight dimensions of fair and adequate payment, a safe and healthy work environment, provision of continuous growth and safety, lawfulness in the organization, social affiliation of work life, general space of work life, integrity and social cohesion in the organization, and development of human capabilities [21], in which the mean score of less than 50 was considered low, between 50 and 90 as moderate, and over 90 as high; and the Cammann's questionnaire which was used to measure the intention to leave the job consisted of six questions in social, individual, and environmental dimensions [22], in which the mean score of less than 10 was considered low, between 10 and 20 as moderate and over 20 as high.

The 5-point Likert scale was used to measure the mentioned variables through three questionnaires used, in which 1 referred to "completely disagree" or "very little" and 5 to "completely agree" or "very high". The demographic data of the participating physicians were also collected.

The validity and reliability of the questionnaires had been verified and confirmed in previous domestic studies through getting experts' opinion, as well as using Cronbach's alpha for Porter's Organizational Commitment, Walton's Quality of Work Life, and Camman's Intention to Leave the Job questionnaires at $0.84,0.86$ and 0.91 , respectively [17, 21, 23].

The collected data were analyzed using SPSS version 23.0 through the Shapiro Wilk test, Independent-Samples $t$-Test, ANOVA, Pearson correlation coefficient and multiple linear regression of $\mathrm{OC}$ and QWL on the intention to leave the job (Backward method). A $p$-value $<0.05$ was considered to be significant.

\subsection{Ethics}

The present study was approved by the Ethics Committee of Shiraz University of Medical Sciences (Project No.: 95-01-01-11303). Oral informed consent was obtained from all participants in this study and all of them were assured of the confidentiality of their responses.

\section{RESULTS}

Of the 268 distributed questionnaires, 253 questionnaires were completed and returned to the researchers. The results showed that the majority of physicians were male $(64 \%)$, married $(90.1 \%)$, at the age group of 41-60 years $(74.3 \%)$, formal and official employees (32.4\%), at the work experience group of 11-20 years (47\%), and had less than 5 years of experience in the family physician program $(85.8 \%)$ (Table 1$)$.

The results of the Shapiro Wilk test showed that the dependent variable, i.e. the intention to leave the job, was normal ( $p$-value $>0.05$ ). According to the results, the mean score of OC was $45.18 \pm 8.26$, indicating a moderate level. Among the dimensions of this variable, the highest and lowest means were related to the normative commitment $(16.24 \pm$ 3.22 ), and effective commitment $(13.93 \pm 4.97)$, respectively. In addition, the mean score of QWL was $65.51 \pm 14.92$, indicating a moderate level. Among the dimensions of QWL, social integration $(9.81 \pm 2.49)$ had the highest mean and the fair and adequate payment $(6.65 \pm 2.50)$ had the lowest one. In this study, the mean score of the intention to leave the job amongst family physicians was also at a moderate level of $16.35 \pm 6.66$ (Table 2).

Table 1. Demographic characteristics of the participants $(n=253)$.

\begin{tabular}{|c|c|c|}
\hline \multicolumn{2}{|c|}{ Variable } & Frequency $(\%)$ \\
\hline \multirow[t]{2}{*}{ Gender } & Male & $162(64 \%)$ \\
\hline & Female & $91(36 \%)$ \\
\hline \multirow[t]{4}{*}{ Marital status } & Married & $228(90.1 \%)$ \\
\hline & Single & $21(8.3 \%)$ \\
\hline & Divorced & $3(1.2 \%)$ \\
\hline & Widow/ widower & $1(0.4 \%)$ \\
\hline \multirow[t]{5}{*}{ Age group (years) } & $<31$ & $17(6.7 \%)$ \\
\hline & $31-40$ & $26(10.3 \%)$ \\
\hline & $41-50$ & $112(44.27 \%)$ \\
\hline & $51-60$ & $76(30.03 \%)$ \\
\hline & $>60$ & $22(8.7 \%)$ \\
\hline \multirow[t]{5}{*}{ Type of employment } & Formal and official & $82(32.4 \%)$ \\
\hline & Contractual & $80(31.6 \%)$ \\
\hline & Private & $68(26.9 \%)$ \\
\hline & Treaty & $18(7.1 \%)$ \\
\hline & Apprentice program & $5(2 \%)$ \\
\hline \multirow[t]{5}{*}{ Work experience (years) } & $<5$ & $23(9.1 \%)$ \\
\hline & $6-10$ & $19(7.5 \%)$ \\
\hline & $11-20$ & $119(47 \%)$ \\
\hline & $21-35$ & $84(33.2 \%)$ \\
\hline & $>36$ & $8(3.2 \%)$ \\
\hline \multirow{3}{*}{$\begin{array}{c}\text { Work experience as a family } \\
\text { physician in rural or urban } \\
\text { areas (years) }\end{array}$} & $<5$ & $217(85.8 \%)$ \\
\hline & $6-10$ & $19(7.5 \%)$ \\
\hline & $>11$ & $17(6.7 \%)$ \\
\hline
\end{tabular}

Also, the results showed that there were not any significant associations between the studied family physicians' demographic characteristics and the mean of their intention to leave the job ( $p$-value $>0.05$ ) (Table 3).

Moreover, the results of the Pearson correlation coefficient showed that $\mathrm{OC}$ and QWL had negative and significant correlations with the intention to leave the job $(\mathrm{r}=-0.699, p$ value $<0.001$ and $\mathrm{r}=-0.535, p$-value $<0.001)$ (Table 4).

On the other hand, the results of multiple linear regression of $\mathrm{OC}$ and QWL on the intention to leave the job showed that the QWL and OC had negative and significant associations with the intention to leave the job ( $p$-value $<0.001)$. However, the QWL had a greater association in explaining the dependent variable (Coefficient of $\mathrm{QWL}=-0.348$ vs. Coefficient of $\mathrm{OC}=-0.260$ ) (Table 5). Furthermore, the value of the Adjusted $\mathrm{R}$-square in the regression model was 0.49 . In other words, only $49 \%$ of the dependent variable variations could be explained by changes in the independent variables, namely, the QWL and OC. Therefore, the identified equation to explain this relationship was as follows:

Intention to leave the job $=3.024-0.155 \mathrm{QWL}-0.210 \mathrm{OC}$ 
Table 2. The means and Standard Deviations (SDs) of organizational commitment, quality of work life and intention to leave the job dimensions among the studied family physicians.

\begin{tabular}{|c|c|c|c|c|c|}
\hline Factors & Dimensions & Mean & SD & Minimum & Maximum \\
\hline \multirow{4}{*}{ Organizational Commitment } & Affective & 13.93 & 3.26 & 5 & 25 \\
\hline & Continuous & 15 & 3.4 & 5 & 25 \\
\cline { 2 - 6 } & Normative & 16.24 & 2.58 & 5 & 25 \\
\cline { 2 - 6 } & Total & 45.18 & 8.61 & 15 & 75 \\
\cline { 2 - 6 } & Fair and adequate payment & 6.65 & 2.02 & 3 & 15 \\
\hline \multirow{4}{*}{ Quality of Work Life } & Healthy and safe working environment & 9.52 & 2.08 & 3 & 15 \\
\cline { 2 - 6 } & Providing growth and safety opportunity & 8.19 & 2.24 & 3 & 15 \\
\cline { 2 - 6 } & Lawfulness & 9.21 & 2.97 & 4 & 20 \\
\cline { 2 - 6 } & Social affiliation & 7.12 & 1.84 & 3 & 15 \\
\cline { 2 - 6 } & General space of work life & 7.45 & 1.67 & 3 & 15 \\
\cline { 2 - 6 } & Social integration & 9.81 & 1.99 & 4 & 20 \\
\cline { 2 - 6 } & Developing human capabilities & 8.62 & 2.02 & 3 & 15 \\
\cline { 2 - 6 } & Total & 65.51 & 11.94 & 26 & 130 \\
\hline \multirow{2}{*}{ Intention to leave the job (Total) } & 16.35 & 5.33 & 6 & 30 \\
\hline \multirow{2}{*}{} & & &
\end{tabular}

Table 3. The associations between the demographic characteristics of the studied family physicians and their intention to leave the job.

\begin{tabular}{|c|c|c|c|}
\hline \multicolumn{2}{|c|}{ Variables } & \multirow{2}{*}{$\begin{array}{c}\text { Mean } \pm \text { SD } \\
16.33 \pm 2.59\end{array}$} & \multirow{3}{*}{$\begin{array}{c}\text { Results } \\
\mathrm{t}=-0.059 \\
p \text {-vale }=0.953\end{array}$} \\
\hline \multirow[t]{2}{*}{ Sex } & Male & & \\
\hline & Female & $16.38 \pm 1.71$ & \\
\hline \multirow[t]{2}{*}{ Marital Status } & Single & $15.16 \pm 3.02$ & \multirow{2}{*}{$\begin{array}{c}\mathrm{t}=-0.942 \\
p \text {-value }=0.242\end{array}$} \\
\hline & Married & $16.48 \pm 1.78$ & \\
\hline \multirow[t]{5}{*}{ Age group (year) } & $<31$ & $18.40 \pm 1.66$ & \multirow{5}{*}{$\begin{array}{c}\mathrm{F}=2.7 \\
p \text {-value }=0.089\end{array}$} \\
\hline & $31-40$ & $20.11 \pm 1.70$ & \\
\hline & $41-50$ & $16.94 \pm 2.50$ & \\
\hline & $51-60$ & $14.02 \pm 2.02$ & \\
\hline & $>60$ & $13.41 \pm 2.02$ & \\
\hline \multirow[t]{5}{*}{ Type of employment } & Formal and official & $15.85 \pm 1.49$ & \multirow{5}{*}{$\begin{array}{c}\mathrm{F}=2.43 \\
p \text {-value }=0.068\end{array}$} \\
\hline & Contractual & $15.74 \pm 2.75$ & \\
\hline & Private & $14.81 \pm 3.72$ & \\
\hline & Treaty & $15.61 \pm 2.42$ & \\
\hline & Apprentice program & $11.20 \pm 0.824$ & \\
\hline \multirow[t]{5}{*}{ Work Experience (year) } & $<5$ & $16.43 \pm 2.59$ & \multirow{5}{*}{$\begin{array}{c}\mathrm{F}=0.516 \\
p \text {-value }=0.724\end{array}$} \\
\hline & $6-15$ & $14.36 \pm 1.55$ & \\
\hline & $16-25$ & $16.31 \pm 3.04$ & \\
\hline & $26-35$ & $16.79 \pm 1.85$ & \\
\hline & $>35$ & $16.62 \pm 1.92$ & \\
\hline
\end{tabular}

\section{DISCUSSION}

The implementation of family physician program by the Ministry of Health and Medical Education is part of the fourth development plan in Iran. Based on this program, all basic health services should be provided to the general public by general physicians who work in this program [24]. Considering that human resources play an important role in the development of each program, this study aimed to investigate the associations of OC and QWL with the intention to leave the job by the family physicians in 2017 , Shiraz, Iran.

The results of the multiple linear regression of OC and
QWL on the intention to leave the job showed that QWL and OC had negative and significant associations with the studied family physicians' intention to leave their job.

Table 4. The Correlation of organizational commitment and quality of work life with the intention to leave the job among the studied family physicians.

\begin{tabular}{|c|c|c|}
\hline Factors & $\begin{array}{c}\text { Pearson Correlation } \\
\text { Coefficient }\end{array}$ & $\boldsymbol{p}$-value \\
\hline Organizational commitment (OC) & -0.689 & $<0.001$ \\
\hline Quality of work life (QWL) & -0.535 & $<0.001$ \\
\hline
\end{tabular}


Table 5. The results of the multiple linear regression of OC and QWL on the intention to leave the job among the studied family physicians.

\begin{tabular}{|c|c|c|c|c|c|}
\hline \multirow{2}{*}{ Intention to Leave the Job } & \multicolumn{2}{|c|}{ Unstandardized Coefficients } & Standardized Coefficients & \multirow{2}{*}{ t } & \multirow{2}{*}{$\boldsymbol{p}$-value } \\
\cline { 2 - 5 } & $\mathbf{B}$ & Standard Error & Beta & & \multicolumn{2}{|c|}{--- } & $<.84$ & $<0.001$ \\
\hline Constant & 3.024 & 0.853 & -0.348 & -5.405 & $<0.001$ \\
\hline Quality of Work Life (QWL) & -0.155 & 0.023 & -0.260 & -4.040 & $<0.001$ \\
\hline Organizational Commitment (OC) & -0.210 & 0.042 & & \\
\hline
\end{tabular}

Also, the results of this study indicated that the mean score of organizational commitment of family physicians was at a moderate level. Among the dimensions of organizational commitment, the highest mean was related to the normative commitment. In this regard, the results of Zarei et al. (2016) [25], Bahrami et al. (2016) [26], and Ferrera's (2007) [27] studies showed that the mean score of OC among the staff of the healthcare network and nurses was moderate and the highest mean of OC was related to the normative commitment dimension, which was in line with the present study findings. However, the results of Karami et al.'s study (2017) showed that the highest mean score of nurses' organizational commitment was related to emotional commitment, which was not consistent with the present study results [28]. The study by Hanamaria Cochio et al. (2010) showed that primary care physicians in Finland had a lower organizational commitment than other physicians, which was due to their high expectations, lower control over job activities, and poor partner counseling [29]. One reason for moderate OC of family physicians in the current study might be due to their high workload and a large number of patients. In addition, the results of two studies showed that promotion and development of the job and the feeling of justice in an organization by the employees played an important role in increasing their organizational commitment $[30,31]$. It seems that given the fact that there is no possibility of promotion and career development for family physicians, it can lead to the reduced organizational commitment.

According to our findings, the mean score of QWL was moderate among the studied population. Also, among the QWL dimensions, the highest mean was related to the social integration of work-life and the lowest mean was related to the fair and sufficient payment. In the studies of Arab et al. (2012) [32] and Shabani Nejad et al. (2012) [33], the QWL expressed by the physicians of hospitals affiliated to Tehran University of Medical Sciences and the family physicians of Mazandaran province was also moderate, which is consistent with the present study. However, in the study by Gonzales Baltazar et al. (2015), the QWL of primary care physicians in Mexico was at a high level [34]. The reason for the differences in the results of Baltazar et al. with the results of other studies might be due to the differences in working, cultural and social conditions in the studied populations.

On the other hand, in the studies by Mohammadi et al. (2011) [23] and Zarei et al. (2016) [25], the results showed that the lowest level of satisfaction with the quality of work-life in the studied nursing staff and other healthcare employees was related to the fair and adequate payment, which was similar to those of the present study. Moreover, in the study by
Jaafarpour et al. (2015) [35] that investigated the QWL of nurses, the fair and adequate payment, safe and hygienic work environment, provision of the opportunity for continuous growth and security, lawfulness in the work environment, and the general working environment were at the low level, and development of human capabilities, social affiliation of working life and social integration of working life were moderate, which were in line with the results of the present study.

In this study, the mean score of intention to leave the job among the studied family physicians was moderate, which can be due to The results of Amir Ismaili et al.'s study (2014) showed that $26 \%$ of family physicians had left out their jobs in the past and $77.3 \%$ of family physicians were also willing to leave their jobs in the near future [17]. The results of Hanamaria Cossio et al.'s study (2010) showed that primary care physicians in Finland had a higher intention to leave the job than other physicians [29], which confirm the results of the present study. Hariri et al. (2012) [36], Atashzade Shorideh (2013) [37], and Nikbakht Nasarbabadi et al. (2014) [38] in their studies showed that the intention to leave the job among the studied nursing staff was moderate, and their results were in line with those of the present study. In most of these studies, the reasons for wanting to leave the job were low payments, long hours of work, irregular payments, lack of job security, job stress and heavy workloads, high job responsibilities, lack of opportunities for continuing education, etc. Considering that in the present study, the fair and adequate payment was the most important reason for physicians' dissatisfaction with QWL, it can be argued that the main reason for leaving the job among the studied population was the lack of fair and adequate payment.

Furthermore, our results indicated that there was a negative and significant association between $\mathrm{OC}$ and the intention to leave the job. In this regard, the results of studies by Mir et al. (2002) [39], and Pine and Hoffman (2005) [40] are consistent with those of the present study.

This study, like other studies, had some limitations. This study was a cross-sectional study in which the required data were collected only by completing the questionnaires. Therefore, it is suggested that similar studies should be carried out longitudinally using qualitative methods along with the quantitative ones.

This study, like other studies, had some limitations, including its cross-sectional design and the use of only questionnaires to collect the required data. 


\section{CONCLUSION}

Since the family physician program was implemented with the aim of improving healthcare system in Iran, it is essential to retain and keep physicians as the principal member of this program. As the findings of this study showed, OC and QWL had negative and significant associations with the intention to leave the job. Therefore, paying attention to meeting family physicians' job, individual, and family needs at different levels and observing organizational justice can increase their OC and QWL, which leads to reducing their intention to leave their job.

\section{ETHICS APPROVAL AND CONSENT TO PARTICIPATE}

The study was approved by the Ethics Committee of Shiraz University of Medical Sciences, Iran (Project No.: 95-01-01-11303).

\section{HUMAN AND ANIMAL RIGHTS}

Not applicable.

\section{CONSENT FOR PUBLICATION}

The Oral informed consent was obtained from all participants in this study.

\section{AVAILABILITY OF DATA AND MATERIALS}

The data from this study will be made available by the author on request.

\section{FUNDING}

None.

\section{CONFLICT OF INTEREST}

The authors declare that there is no conflict of interest, financial, or otherwise.

\section{ACKNOWLEDGEMENTS}

The researchers wish to thank all family physicians participating in this study for their kind cooperation with the researchers in collecting and analyzing data, as well as Mr. $\mathrm{H}$. Argasi at the Research Consultation Center (RCC) of Shiraz University of Medical Sciences for his invaluable assistance in editing this manuscript.

\section{REFERENCES}

[1] Homaie Rad E, Delavari S, Aeenparast A, Afkar A, Farzadi F, Maftoon F. Does economic instability affect healthcare provision? evidence based on the urban family physician program in iran. Korean J Fam Med 2017; 38(5): 296-302. [http://dx.doi.org/10.4082/kjfm.2017.38.5.296] [PMID: 29026491]

[2] Doshmangir L, Bazyar M, Doshmangir P, Mostafavi H, Takian A. Infrastructures required for the expansion of family physician program to urban settings in Iran. Arch Iran Med 2017; 20(9): 589-97. [PMID: 29048921]

[3] Kalhor R, Azmal M, Kiaei MZ, Eslamian M, Tabatabaee SS, Jafari M. Situational analysis of human resources in family physician program: Survey from Iran. Mater Sociomed 2014; 26(3): 195-7. [http://dx.doi.org/10.5455/msm.2014.26.195-197] [PMID: 25126016]

[4] Khayyati F, Motlagh ME, Kabir M, Kazemeini H, Gharibi F, Jafari N. The role of family physician in case finding, referral, and insurance coverage in the rural areas. Iran J Public Health 2011; 40(3): 136-9.
[PMID: 23113096]

[5] Dixit V, Bhati M. A study about employee commitment and its impact on sustained productivity in Indian auto-component industry. Eur J Bus Soc Sci 2012; 1(6): 34-51.

[6] Naquin S, Holton E. The effects of personality, affectivity, and work commitment on motivation to improve work through learning. Hum Resour Dev Q 2002; 13(4): 357-76.

[http://dx.doi.org/10.1002/hrdq.1038]

[7] Testa MR. Organizational commitment, job satisfaction, and effort in the service environment. J Psychol 2001; 135(2): 226-36. [http://dx.doi.org/10.1080/00223980109603693] [PMID: 11403344]

[8] McMurray A, Scott D, Pace R. The relationship between organizational commitment and organizational climate in manufacturing. Hum Resour Dev Q 2004; 15(4): 473-88. [http://dx.doi.org/10.1002/hrdq.1116]

[9] Schwepker C. Ethical climate's relationship to job satisfaction, organizational commitment, and turnover intention in the salesforce. $\mathrm{J}$ Bus Res 2001; 54(1): 39-52.

[http://dx.doi.org/10.1016/S0148-2963(00)00125-9]

[10] Faraji O, Salehnejad G, Gahramani S, Valiee S. The relation between nurses' quality of work life with intention to leave their job. Nurs Pract Today 2017; 4(2): 103-11.

[11] Duad N. Investigating the relationship between quality of work life and organizational commitment amongst employees in Malaysian firms. Int J Bus Manage 2010; 5(10): 75-82

[http://dx.doi.org/10.5539/ijbm.v5n10p75]

[12] Dargahi H, Changizi V, Jazayeri Gharabagh E. Radiology employees' quality of work life. Acta Med Iran 2012; 50(4): 250-6. [PMID: 22592575]

[13] Saraji G, Dargahi H. Study of quality of work life (QWL). Iran J Public Health 2006; 35(4): 8-14.

[14] Hannif Z, Burgess J, Connell J. Call centres and the quality of work life: Towards a research agenda. J Ind Relat 2008; 50(2): 271-84. [http://dx.doi.org/10.1177/0022185607087902]

[15] Herrera Sánchez R, Cassals Villa M. Algunos factores influyentes en la calidad de vida laboral de enfermería. Rev Cubana Enferm 2005; 21(1): 1-10.

[16] Degen C, Li J, Angerer P. Physicians' intention to leave direct patient care: An integrative review. Hum Resour Health 2015; 13(1): 74-85. [http://dx.doi.org/10.1186/s12960-015-0068-5] [PMID: 26350545]

[17] Amiresmaili M, Khosravi S, Feyzabadi VY. Factors affecting leave out of general practitioners from rural family physician program: A case of Kerman, Iran. Int J Prev Med 2014; 5(10): 1314-23. [PMID: 25400891]

[18] Arab M, Shafiee M, Iree M, Safari H, Habibi F, Akbari Sari A, et al. Surveying the attitude of family physicians working in health centers of Tehran University of Medical Sciences towards their profession using a qualitative approach. Hospital 2013; 12(3): 19-28.

[19] Behzadifar M, Behzadifar M, Heidarvand S, et al. The challenges of the family physician policy in Iran: A systematic review and metasynthesis of qualitative researches. Fam Pract 2018; 35(6): 652-60. [http://dx.doi.org/10.1093/fampra/cmy035] [PMID: 29741692]

[20] Yousef D. Validating the dimensionality of Porter et al.'s measurement of organizational commitment in a non-Western culture setting. Int J Hum Resour Manage 2003; 14(6): 1067-79.

[http://dx.doi.org/10.1080/0958519032000106218]

[21] Esmaeli Lahmali A. A study of relationship between Quality of Work Life (QWL) and performance of the staff in mazandaran provin tax affairs general directoratece. J Tax Res 2013; 16(67): 171-95.

[22] Farhadi A, Movahedi Y, Nalchi M, Daraei M, Mohammadzadegan R. The relationship between Work-family conflict, burnout dimensions and intention to leave among female nurses. Iran J Nurs 2013; 26(84): $34-43$.

[23] Mohammadi A, Sarhanggi F, Ebadi A, Daneshmandi M, Reiisifar A Amiri F, et al. Relationship between psychological problems and quality of work life of Intensive Care Unit Nurses. Iran J Crit Care Nurs 2011; 4(3): 135-40.

[24] Shiri M, Asgari H, Talebi M, Rohani M, Narimani S. Educational needs assessment of family (general) physicians working in rural health centers of esfahan districts in five domains. ran. J Med Educ 2011; 10(5): 726-34.

[25] Zarei E, Ahmadi F, Danshkohan A, Ramezankhani A. The correlation between organizational commitment and the quality of working life among staff of Sarpolzahab health network. J Healthc Prot Manage 2016; 5(2): 61-9.

[26] Bahrami MA, Barati O, Ghoroghchian MS, Montazer-Alfaraj R, Ranjbar Ezzatabadi M. Role of organizational climate in 
organizational commitment: The case of teaching hospitals. Osong Public Health Res Perspect 2016; 7(2): 96-100.

[http://dx.doi.org/10.1016/j.phrp.2015.11.009] [PMID: 27169007]

[27] Ferreira MM. Nurses organizational commitment: The discriminating power of gender. Nurs Adm Q 2007; 31(1): 61-7.

[http://dx.doi.org/10.1097/00006216-200701000-00014] [PMID: 17198121]

[28] Karami A, Farokhzadian J, Foroughameri G. Nurses' professional competency and organizational commitment: Is it important for human resource management? PLoS One 2017; 12(11)e0187863

[http://dx.doi.org/10.1371/journal.pone.0187863] [PMID: 29117271]

[29] Kuusio H, Heponiemi T, Sinervo T, Elovainio M. Organizational commitment among general practitioners: A cross-sectional study of the role of psychosocial factors. Scand J Prim Health Care 2010; 28(2): 108-14

[http://dx.doi.org/10.3109/02813431003779647] [PMID: 20470018]

[30] Rhoades L, Eisenberger R. Perceived organizational support: A review of the literature. J Appl Psychol 2002; 87(4): 698-714.

[http://dx.doi.org/10.1037/0021-9010.87.4.698] [PMID: 12184574]

[31] Ravangard R, Sajjadnia Z, Ansarizade N. Study of the effects of perceived organizational justice and its components on organizational commitment of administrative and financial employees of Shiraz University of Medical Sciences general hospitals in 2012. Arch Pharm Pract (Mumbai) 2013; 4(1): 35-43.

[http://dx.doi.org/10.4103/2045-080X.111580]

[32] Arab M, Shabaninejad H, Rashidian A, Rahimi A, Purketabi K. A survey on working life quality of specialists working in affiliated hospitals of TUMS. Hospital 2013; 11(4): 19-24.

[33] Shabaninejad H, Arab M, Rashidian A, Zeraati H, Bahrami S. Quality of working life of Family Physicians in Mazandaran. Hakim Res J 2012; 15(2): 178-84.

[34] González-Baltazar R, Hidalgo-Santacruz G, León-Cortés S, ContrerasEstrada M, Aldrete-Rodríguez M, Hidalgo-González B, et al. Quality of work life and mental health in primary care physicians. Procedia Manuf 2015; 3: 4935-40. [http://dx.doi.org/10.1016/j.promfg.2015.07.634]

[35] Jaafarpour M, Khani A, Mahmodian M. Evaluation of the quality of nursing work life and its association with job burnout in Isfahan University of Medical Sciences. Int J Epidemiol Res 2015; 2(1): 30-9.

[36] Hariri G, Yaghmaei F, Shakeri N. Assessment of some factors related to leave in nurses and their demographic charater in educational hospitals of Shahid Behesthi University of Medical Sciences. J Health Prot Manage 2012; 1(3): 17-27.

[37] Atashzadeh Shorideh F, Ashktorab T, Yaghmaei F, Alavimajd H. Association of ICU nurses' demographic characteristics and moral distress. Iran J Med Ethics Hist Med 2013; 5(7): 66-78.

[38] Nikbakht Nasrabadi A, Salari A, Hosseinpour M, Yekaninejad M. Study the rate of burnout and intention to leave and their relationship among emergency department nurses. Iran J Nurs Res 2014; 9(3): 19-29.

[39] Meyer J, Stanley D, Herscovitch L, Topolnytsky L. Affective, continuance, and normative commitment to the organization: A metaanalysis of antecedents, correlates, and consequences. J Vocat Behav 2002; 61(1): 20-52.

[http://dx.doi.org/10.1006/jvbe.2001.1842]

[40] Payne S, Huffman A. A longitudinal examination of the influence of mentoring on organizational commitment and turnover. Acad Manage J 2005; 48(1): 158-68.

[http://dx.doi.org/10.5465/amj.2005.15993166]

\section{2019 Rezaee et al.}

This is an open access article distributed under the terms of the Creative Commons Attribution 4.0 International Public License (CC-BY 4.0), a copy of which is available at: (https://creativecommons.org/licenses/by/4.0/legalcode). This license permits unrestricted use, distribution, and reproduction in any medium, provided the original author and source are credited. 